\title{
A comparative study of the effect of body mass index on pregnancy outcomes in normal and overweight women
}

\author{
Seeniammal P.*, Chellamma V. K., Umadevi N.
}

Department of Obstetrics and Gynecology, Government Medical College, Calicut, Kerala, India

Received: 09 February 2017

Accepted: 07 March 2017

\author{
*Correspondence: \\ Dr. Seeniammal P., \\ E-mail: hidoc_mmc@yahoo.co.in
}

Copyright: (c) the author(s), publisher and licensee Medip Academy. This is an open-access article distributed under the terms of the Creative Commons Attribution Non-Commercial License, which permits unrestricted non-commercial use, distribution, and reproduction in any medium, provided the original work is properly cited.

\begin{abstract}
Background: Maternal obesity has been reported as a risk factor for various antepartum, intrapartum, postpartum and neonatal complications. Increasing rates of overweight among pregnant women are a significant public health concern with various implications for prenatal care and supervision of delivery. Therefore, the present study is to determine the adverse materno-fetal outcome in primigravid overweight and obese women delivering singleton babies.

Methods: A prospective comparative study was conducted for a year at $\mathrm{IMCH}$, Medical College, Calicut. Primigravid women with a singleton uncomplicated pregnancy with cephalic presentation at $\geq 37$ weeks of gestation with accurate information regarding height and weight recorded at the booking visit were included in the study. Comparisons were made between 100 women with BMI > 25 and 200 women with BMI 18.5-24.9. Statistical analysis was done using SPSS version 16.0. Data was analysed by Pearson Chi square test and Fisher's exact test.

Results: Overweight mothers are at increased risk quoted as relative risk (RR) and 95\% confidence intervals (CI) of adverse materno-fetal outcomes. Gestational hypertension RR 2.39 (CI 1.65-3.47), Gestational diabetes RR 2.67(CI 0.95-7.48), induction of labour RR 2.35 (CI 1.4-3.95), Cesarean section RR 5.73 (CI 3.76-8.73), macrosomia RR 14 (CI 1.75-112.23), NICU admissions RR 4.51(CI 2.61-7.84),perineal lacerations RR 4.72 (CI 1.15-20.4), wound infection RR 2.97 (CI 1.06-8.41), and prolonged hospital stay.

Conclusions: It is clearly evident from the study that maternal overweight and obesity is associated with adverse materno-fetal outcome.
\end{abstract}

Keywords: Overweight, Obesity, Pregnancy

\section{INTRODUCTION}

In numerical terms, we are now in the midst of the greatest epidemic ever experienced by humans. Rates of overweight and obesity, together with a host of their related disorders, are increasing rapidly throughout much of the world. The latest reports of the World Health Organization (WHO) indicate that in 2005, approximately 1.6 billion adults were overweight and at least 400 million adults were obese - a major contributor to global burden of chronic disease and disability. ${ }^{1}$ Overweight and obesity has also reached epidemic proportions in India in $21 \mathrm{st}$ century, affecting $5 \%$ of country's population. In India,
$26 \%$ of pregnant women are overweight and $8 \%$ are obese. In India, the percentage of women who are overweight or obese is highest in Punjab (30\%), followed by Kerala (28\%) and Delhi (26\%) National Family Health Survey, NFHS-3 2005-2006. ${ }^{2}$

Maternal overweight has been reported as a risk factor for various antepartum, intrapartum, postpartum and neonatal complications such as gestational diabetes mellitus, gestational hypertension, antepartum haemorrhage, induction of labour, and prolonged duration of labour, Caesarean section rates, postpartum haemorrhage, shoulder dystocia, macrosomia and neonatal 
admissions. ${ }^{3-5}$ Increasing rates of overweight among pregnant women are a significant public health concern with various implications for prenatal care and supervision of delivery. Therefore, the present study is to determine the adverse materno-fetal outcome in primigravid overweight and obese women delivering singleton babies.

The aim of the study was:

- To compare the incidence of complications in the antepartum, intrapartum and postpartum period in patients with overweight and obesity with that of patients with normal body mass index.

- To compare the perinatal outcome in patients with overweight and obesity with that of patients with normal body mass index.

\section{METHODS}

We conducted a prospective comparative study for one year at Department of Obstetrics and Gynaecology, Institute of Maternal and Child Health, Government Medical College, Calicut after ethical committee approval. All primigravidas with singleton pregnancy admitted at $\geq 37$ weeks of gestation with accurate weight and height recorded at 1 st booking visit were included and were categorized into two groups. Study group: 100 primigravidas with $\mathrm{BMI} \geq 25$. Control group: 200 uncomplicated primigravidas with BMI between 18.5 24.99. Excluded were all multigravidas, primigravidas with multiple pregnancies and malpresentations, primigravidas with history of medical illness and who were underweight and who do not have accurate weight and height recordings in the 1st trimester. A detailed written informed consent obtained from the participants before they were included in the study. During the study period, total number of deliveries were 12,580. Of these, total number of primigravidas were 6416. With exclusion criteria taken into consideration, the number reduced to 3099. Of these, 100 primigravidas with $\mathrm{BMI} \geq 25$ and 200 primigravidas with BMI between 18.5 - 24.99 were selected by systematic random sampling method. A detailed history including the demographic characteristics of the patients were taken and systemic examination done. Outcomes assessed included gestational hypertension, gestational diabetes, induction of labour, prolonged labour, Cesarean section rates, postpartum hemorrhage, wound infection, macrosomia and neonatal admissions in both the groups and results analysed.

\section{Statistical analysis}

Statistical analysis done using SPSS version 16.0. Data was analysed by Pearson Chi Square test and Fisher's exact $t$ test. A p value $<0.05$ was significant. Relative risk (RR) and Confidence Interval (CI) were used to quantify the risk.

\section{RESULTS}

Of the 100 patients in the study group, $85 \%$ were overweight and $15 \%$ were obese. All obese patients belonged to class I obese group (BMI 30-34.9).

\section{Demographic variables}

Age

Although majority of mothers in both study and control groups were between $21-30$ years of age, $9 \%$ of mothers in study group and only $0.5 \%$ of mothers in the control group were between 31-35 years of age and this difference was statistically significant with $\mathrm{p}$ value $=0.00001$.

\section{Occupation}

$85 \%$ of mothers in the study group and only $73 \%$ of mothers in control group had sedentary occupation and this difference was statistically significant with $\mathrm{p}$ value $=$ 0.016 .

\section{Residence}

$80 \%$ of mothers in the study group and only $59 \%$ of mothers in the control group were residing in urban area and this difference was statistically significant with a $\mathrm{p}$ value $=0.00001$

\section{Weight gain during pregnancy}

\section{Weight gain}

$\geq 13 \mathrm{~kg}$ during pregnancy was seen in $52 \%$ of the study group when compared to only $11 \%$ of the control group and this difference was statistically significant with a $\mathrm{p}$ value $=0.00001$.

\section{Infertility}

$29 \%$ of women in the study group and only $4.5 \%$ of women in control group were treated for infertility and the difference was statistically significant with a $\mathrm{p}$ value $=$ 0.003 , the main cause for infertility being polycystic ovarian disease.

\section{Fetomaternal outcome}

\section{Antenatal complications}

Hypertensive disorders and diabetes mellitus were the two most common antenatal complications encountered in the study group (Table 1 and 2).

\section{Type of labour}

$60 \%$ of mothers in the study group had their labour induced when compared to only $39 \%$ in the control group 
and this difference was statistically significant with a relative risk of 2.35 and $95 \%$ confidence interval $1.4-3.95$ and $\mathrm{p}$ value $=0.0006$.

Mode of delivery

$63 \%$ of mothers in the study had Cesarean section when compared to only $11 \%$ in the control group with a RR$5.73,95 \%$ CI 3.76-8.73 and a p value $=0.00006$.

Mean first stage duration: Mean first stage duration is prolonged significantly in the study group (7.4 hours) when compared to the control group (5.8 hours).
Indications for cesarean section

The three most common statistically significant indications for Cesarean Section were failed induction, failure to progress and prolonged period of infertility in the study group (Table 3 ).

\section{Macrosomia and NICU admission}

Macrosomia and NICU admissions were also found to be statistically significant in the study group (Table 4).

Table 1: Antenatal complications - hypertensive disorders.

\begin{tabular}{|ll|llll|}
\hline $\begin{array}{l}\text { Antenatal } \\
\text { complication }\end{array}$ & $\begin{array}{l}\text { Study } \\
\text { incidence }\end{array}$ & $\begin{array}{l}\text { Control } \\
\text { incidence }\end{array}$ & $\begin{array}{l}\text { Relative risk } \\
{[R R]}\end{array}$ & $\begin{array}{l}95 \% \text { Confidence } \\
\text { Interval [C] }\end{array}$ & p Value \\
\hline Gestational hypertension & $43 \%$ & $12 \%$ & 2.39 & $1.65-3.47$ & 0.00001 \\
\hline Pre eclampsia & $15 \%$ & $0.5 \%$ & 30 & $4.02-223.9$ & 0.0001 \\
\hline
\end{tabular}

Table 2: Antenatal complications - diabetes mellitus.

\begin{tabular}{|llllll|}
\hline $\begin{array}{l}\text { Antenatal } \\
\text { complication }\end{array}$ & $\begin{array}{l}\text { Study } \\
\text { Incidence }\end{array}$ & $\begin{array}{l}\text { Control } \\
\text { Incidence }\end{array}$ & $\begin{array}{l}\text { Relative Risk } \\
\text { [RR] }\end{array}$ & $\begin{array}{l}\text { 95\% Confidence } \\
\text { Interval [CI] }\end{array}$ & $\begin{array}{l}\text { p Value } \\
\text { Impaired glucose tolerance }\end{array}$ \\
\hline Gestational diabetes & $8 \%$ & $2 \%$ & 4 & $1.23-12.97$ & 0.0168 \\
\hline Pre-Gestational diabetes & $4 \%$ & $3 \%$ & 2.67 & $0.95-7.48$ & 0.05 \\
\hline
\end{tabular}

Table 3: Indications for cesarean section.

\begin{tabular}{|lllll|l|}
\hline Indication for Cesarean section & $\begin{array}{l}\text { Study } \\
\text { Incidence }\end{array}$ & $\begin{array}{l}\text { Control } \\
\text { Incidence }\end{array}$ & $\begin{array}{l}\text { Relative Risk } \\
{[R R]}\end{array}$ & $\begin{array}{l}\text { 95\% Confidence } \\
\text { Interval [CI] }\end{array}$ & p Value \\
\hline Failed Induction & $21 \%$ & $4.5 \%$ & 4.67 & $2.22-9.81$ & 0.00001 \\
\hline Failure to progress & $21 \%$ & $4 \%$ & 5.25 & $2.41-11.43$ & 0.00001 \\
\hline Prolonged period of Infertility & $12 \%$ & $0.5 \%$ & 24 & $3.17-181.98$ & 0.00001 \\
\hline
\end{tabular}

Table 4: Macrosomia and NICU admission.

\begin{tabular}{|llllll|}
\hline Parameter & $\begin{array}{l}\text { Study } \\
\text { Incidence }\end{array}$ & $\begin{array}{l}\text { Control } \\
\text { Incidence }\end{array}$ & $\begin{array}{l}\text { Relative Risk } \\
{[\mathrm{RR}]}\end{array}$ & $\begin{array}{l}95 \% \text { Confidence } \\
\text { Interval [CI] }\end{array}$ & $\begin{array}{l}\text { p Value } \\
\text { Birth weight }>4 \mathrm{~kg}\end{array}$ \\
\hline NICU admission & $5 \%$ & $0.5 \%$ & 14 & $1.75-112.23$ & 0.0023 \\
\hline
\end{tabular}

Table 5: Postpartum complications.

\begin{tabular}{|llllll|}
\hline Postpartum complications & $\begin{array}{l}\text { Study } \\
\text { Incidence }\end{array}$ & $\begin{array}{l}\text { Control } \\
\text { Incidence }\end{array}$ & $\begin{array}{l}\text { Relative Risk } \\
\text { [RR] }\end{array}$ & $\begin{array}{l}\text { 95\% Confidence } \\
\text { Interval [CI] }\end{array}$ & $\begin{array}{l}\text { p Value } \\
\text { Wound infection }\end{array}$ \\
\hline Perineal laceration & $10 \%$ & $4 \%$ & 2.97 & $1.06-8.41$ & 0.019 \\
\hline Postpartum hemorrhage & $4 \%$ & $1 \%$ & 4.72 & $1.15-20.4$ & 0.018 \\
\hline
\end{tabular}

\section{Postpartum complications}

The three statistically significant postpartum complications in the study group were wound infection, perineal lacerations and postpartum hemorrhage (Table 5). 


\section{Prolonged hospital stay}

Incidence of prolonged hospital stay was $35 \%$ in the study group when compared to only $19 \%$ in the control group with a statistically significant $\mathrm{p}$ value $=0.001$.

\section{DISCUSSION}

The average BMI is increasing among all age categories and women are entering pregnancy at higher weights. Human pregnancy is an insulin-resistant condition by itself, potentially compounded by increased pre-gravid insulin resistance in obese women. There is a $40 \%$ to $50 \%$ increase in insulin resistance during pregnancy (from pregravid condition). ${ }^{6}$ It is now universally acknowledged that maternal overweight and obesity are linked with adverse pregnancy outcome. Maternal complications include hypertension, diabetes, respiratory complications (asthma and sleep apnea), thromboembolic disease, more frequent cesarean delivery with increased postpartum hemorrhage and wound infection.

Newborn complications include congenital malformations, large-for gestational-age (LGA) infants, stillbirths, shoulder dystocia, and long-term adolescent complications (obesity and diabetes). A discussion of these complications should be the balance between the benefit/risk ratio of fetal and maternal perspectives.

In a population based cohort study conducted by Beaten et al, to assess the pregnancy complications and outcomes in overweight and obese women, weight gain during pregnancy was above normal in $41.8 \%$ of the control group and $63.4 \%$ of the study group. ${ }^{7}$

In a retrospective case control study conducted by Sara Sukalich et al gestational hypertension and preeclampsia were statistically higher ( $\mathrm{p}$ value $<0.05$ ) in the study group with an odds ratio of $1.8,95 \%$ CI (1.4-2.3) for gestational hypertension and with an odds ratio of $1.7,95 \%$ CI (1.22.4) for preeclampsia. ${ }^{8}$

In a study conducted to assess the prevalence of overweight and obesity in an Australian obstetric population, conducted by Callaway et al. and retrospective cohort study conducted by Sebire et al gestational diabetes was significantly higher in their study population with a $\mathrm{p}$ value $<0.05$, with an odds ratio $1.78,95 \% \mathrm{CI}(1.25-2.52)$ and odds ratio $1.68,95 \% \mathrm{CI}(1.53-1.84)$ respectively in each of the studies. 5,9

In a study conducted by Sebire et al and Nova Scotia et al induction of labour was significantly higher in the study group with a pvalue $<0.05$ with an odds ratio $2.14,95 \% \mathrm{CI}$ (1.86-2.04) and odds ratio $1.94,95 \%$ CI (1.86-2.04) respectively in each of the studies. ${ }^{5}$ In a study conducted by Usha Kiran et al, mean duration of labour was 8.09 hours in the study group with BMI $>30$ and 7.7 hours in the control group with BMI-20-30. ${ }^{10}$
The Cesarean section rates were significantly higher in obese mothers in the studies conducted by Usha kiran et al. and Owens LA et al with an odds ratio 1.6 and 1.57 respectively and 95\%CI 1.4-2 and 1.24-1.98 respectively. In a study conducted by Usha kiran et al, macrosomia and NICU admissions were statistically significant with an odds ratio $2.1,95 \%$ CI 1.6-2.6 for macrosomia and odds rato $1.5,95 \%$ CI $1.09-2.3$ for NICU admission respectively. ${ }^{10}$ Post partum complications like postpartum hemorrhage was significantly higher in the obese mothers in the study conducted by Usha kiran et al and wound infection in the study conducted by $\mathrm{Yu}$ et al with an odds ratio of 1.5 and $95 \%$ CI 1.2-1.8 for postpartum hemorrhage and odds ratio $1.27,95 \%$ CI $1.09-1.48$ for wound infection respectively. Prolonged hospital stay was also significantly high in a study conducted by Perlow JH et al with a $p$ value of 0.0003 .

\section{CONCLUSION}

The developing world is being seized by the epidemic, obesity. The dramatic increase in the prevalence of obesity in pregnancy is of significant public health concern. Obesity in pregnancy is associated with increased rate of antepartum, intrapartum, postpartum complications in the mother and adverse outcome in the neonate as well.

The potential of in utero therapy and prevention of fetal macrosomia, possibly through lifestyle measures before and during gestation, and achieving a desired level of glycemic control in pregnancies complicated with diabetes, should become a research focus of considerable interest relative to the short- and long-term prevention of obesity and progression into overt diabetes and metabolic syndrome.

The implications of maternal obesity far surpass intrauterine life, extending into infancy, childhood and even adulthood with severe health repercussions. Prevention rather than treatment may offer the best hope of breaking the vicious cycle of obesity during pregnancy - "THE BATTLE OF THE BULGE".

\section{Funding: No funding sources}

Conflict of interest: None declared

Ethical approval: The study was approved by the Institutional Ethics Committee

\section{REFERENCES}

1. World Health Organization. Obesity: preventing and managing the global epidemic. Geneva (Switzerland): World Health Organization; WHO technical report series; 2000:894.

2. Third National Family Health Survey. Mumbai: International Institute for Population Sciences. 2006. Available from: http://nfhsindia.org/nfhs3_national_report.html

3. Bhattacharya S, Campbell DM, Liston WA. Effect of body mass index on pregnancy outcomes in 
nulliparous women delivering singleton babies. BMC Public Health. 2007;24(7):168.

4. Anna-Maria Siega-Riz, Barbaria, Laraia. The implications of maternal overweight and obesity on the course of pregnancy and birth outcomes. Matern Child Health J. 2006;10:S153-156.

5. Sebire NJ, Jolly M, Harris JP. Maternal obesity and pregnancy outcome: a study of 287,213 pregnancies in London. Int J Obes. 2001;25:1175-82.

6. Catalano P. Editorial. Obesity and pregnancy-the propagation of a vicious cycle? J Clin Endocrinol Metab. 2003;88(8):3505-6.

7. Baeten JM, Bukusi EA, Lambe M. Pregnancy complications and outcomes among overweight and obese nulliparous women. Am J Public Health. 2001;91:436-40.
8. Sara Sukalich, Mingione MJ, Glantz JC. obstetric outcomes in overweight and obese adolescents AJOG. 2006;195:851-5.

9. Callaway LK, Prins JB, Chang AM, McIntyre HD. The prevalence and impact of overweight and obesity in an Australian obstetric population. Med J Aust. 2006;184:56-59.

10. Outcome of pregnancy in a woman with an increased body mass index. Usha Kiran TS; Hemmadi S; Bethel J; Evans J BJOG. 2005 Jun;112(6):768-72.

Cite this article as: Seeniammal $\mathrm{P}$, Chellamma VK, Umadevi NA. A comparative study of the effect of body mass index on pregnancy outcomes in normal and overweight women. Int J Reprod Contracept Obstet Gynecol 2017;6:1550-1554. 